\section{Ein neues Werkzeug zur Verwaltung des Honorarmangels?}

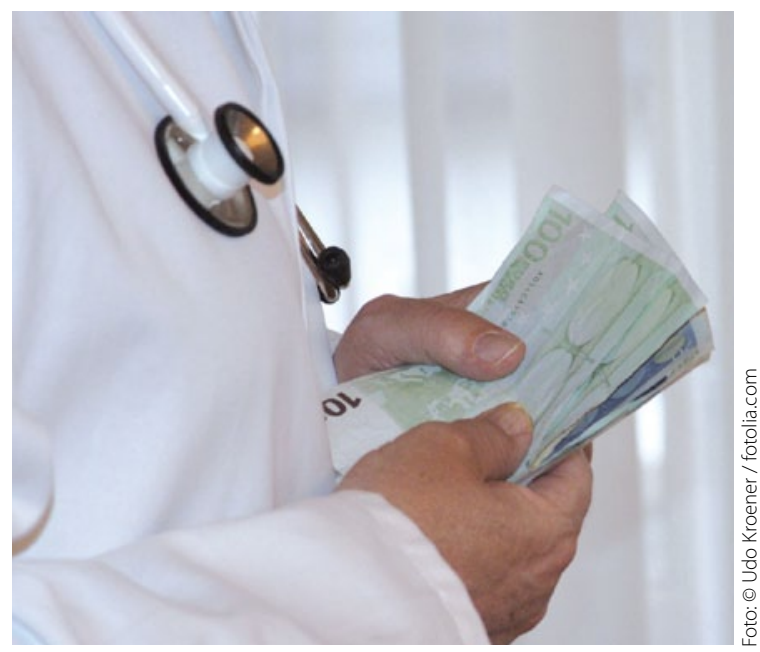

- Mit dem Versorgungsstrukturgesetz (VStG) wurde $\mathrm{zu}$ Jahresbeginn die Honorarverteilung wieder auf die KVEbene verlegt. Neun KVen haben eine Einschätzung abgegeben, was die wieder gewonnene regionale Verantwortung für die Honorare an Vorteilen, aber auch an Nachteilen bringt.

\section{Regionale Besonderheiten können einfließen}

Das Ergebnis: Bei den KVen Hamburg, Schleswig-Holstein, Berlin, Sachsen, Sachsen-Anhalt, Nordrhein, Saarland, Rheinland-Pfalz und Baden-Württemberg stößt der Wunsch des Gesetzgebers, die Regionen wieder stärker in die Beurteilung und Vergabe der ärztlichen Honorare einzubinden, generell auf $\mathrm{Zu}$ stimmung. Denn, so die einstimmige Meinung, nun könnten wieder regionale Besonderheiten in die Honorare einflieBen.

Doch die Vergütungsunterschiede, die noch vor der letzten Reform beschlossen wurden, ließen sich in regio- nalen Verhandlungen mit den Kassen nicht ausgleichen, bemängelt die KV Nordrhein. Noch drastischer drückt es die KV Sachsen-Anhalt aus: Da die regionale Morbidität bei der Gesamtvergütung 2012 gar nicht anerkannt werde, fürchtet die KV, dass der Honorarverteilungsmaßstab „ein Instrument zur Verteilung des Mangels an Honorar bleibt“.

\section{Manche KVen verhandeln gerne direkt mit den Kassen}

Doch nicht alle KVen sehen so düster. „In direkten Verhandlungen mit den Krankenkassen lässt sich das Maximale herausholen“, sagt Walter Plassmann, stellvertretender Vorsitzender der KV Hamburg (KVHH). Ähnliche Töne sind aus Baden-Württemberg zu hören.

Bei der KV Saarland ist man hingegen noch gar nicht so sicher, ob der regionale Spielraum so groß sein wird, weil auch mit dem VStG zunächst die KBV die Vorgaben für die Honorarverteilung festlegt.

REH a
Kündigung unwirksam wegen Einschreiben - Eine Kündigung per Übergabe-Einschreiben ist ein Risiko für den Arbeitgeber. Holt der Arbeitnehmer die Sendung nicht ab, gilt die Kündigung als nicht zugegangen, wie das Landesarbeitsgericht (LAG) Rheinland-Pfalz kürzlich entschied (Az.: 10 Sa 156/11). Damit gab das LAG einer Klägerin recht. Der Arbeitgeber wollte ihr mit Übergabe-Einschreiben kündigen. Ein solches Einschreiben wird persönlich zugestellt. Weil niemand aufmachte, hinterließ der Postbote eine Benachrichtigung. Die Klägerin holte das Schreiben aber nicht ab. Daher ist es ihr auch nicht zugegangen und die Kündigung unwirksam, so das LAG

MWO a

Überstunden: Riegel vorschieben oder bezahlen! Ärzte, die Mitarbeiter sehenden Auges Überstunden machen lassen, müssen diese auch bezahlen, so das Landesarbeitsgericht (LAG) Berlin-Brandenburg (Az.: 6 Sa 1941/11). Das LAG sprach einer Angestellten 4370 Euro für 372 Überstunden zu. Zu Beginn des Arbeitsverhältnisses hatte ihr Vorgesetzter sie angewiesen, Beginn und Ende ihrer täglichen Arbeitszeit aufzuschreiben. Das tat sie auch.

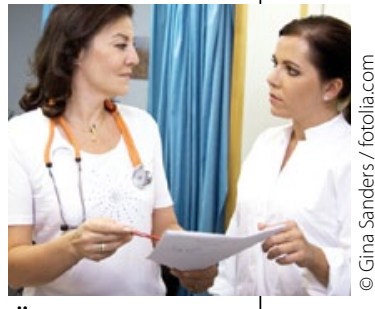
Die Firma wollte die dokumentierten Überstunden aber nicht bezahlen. Das muss sie laut LAG aber. Denn der Chef habe die Überstunden geduldet und hingenommen, dass die Angestellte über ihre reguläre Arbeitszeit hinaus im Betrieb war.

MWO = 